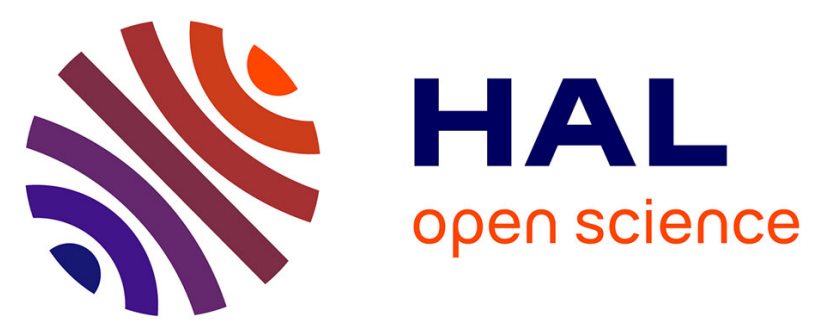

\title{
Pathophysiology of the behavioral variant of frontotemporal lobar degeneration: A study combining MRI and FDG-PET
}

Marie-Sonia Buhour, Franck Doidy, Mickael Laisney, Anne-Lise Pitel, Vincent de La Sayette, Fausto Viader, Francis Eustache, Béatrice Desgranges

\section{To cite this version:}

Marie-Sonia Buhour, Franck Doidy, Mickael Laisney, Anne-Lise Pitel, Vincent de La Sayette, et al.. Pathophysiology of the behavioral variant of frontotemporal lobar degeneration: A study combining MRI and FDG-PET. Brain imaging and behavior (Brain Imaging Behav), 2016, 11 (1), pp.240-252. 10.3233/JAD-2012-121156 . inserm-01511515

\section{HAL Id: inserm-01511515 https://www.hal.inserm.fr/inserm-01511515}

Submitted on 21 Apr 2017

HAL is a multi-disciplinary open access archive for the deposit and dissemination of scientific research documents, whether they are published or not. The documents may come from teaching and research institutions in France or abroad, or from public or private research centers.
L'archive ouverte pluridisciplinaire HAL, est destinée au dépôt et à la diffusion de documents scientifiques de niveau recherche, publiés ou non, émanant des établissements d'enseignement et de recherche français ou étrangers, des laboratoires publics ou privés. 


\section{HAL \\ archives-ouvertes}

\section{Pathophysiology of the behavioral variant of frontotemporal lobar degeneration: A study combining MRI and FDG-PET}

Ms Buhour, F Doidy, F Laisney, F Pitel, F Sayette, F Viader, F Eustache, B Desgranges

\section{- To cite this version:}

Ms Buhour, F Doidy, F Laisney, F Pitel, F Sayette, et al.. Pathophysiology of the behavioral variant of frontotemporal lobar degeneration: A study combining MRI and FDG-PET. Brain Imaging and Behavior, 2017, 2, pp.746 - 252. .

HAL Id: inserm-01511515

http://www.hal.inserm.fr/inserm-01511515

Submitted on 21 Apr 2017

HAL is a multi-disciplinary open access archive for the deposit and dissemination of scientific research documents, whether they are published or not. The documents may come from teaching and research institutions in France or abroad, or from public or private research centers.
L'archive ouverte pluridisciplinaire HAL, est destinée au dépôt et à la diffusion de documents scientifiques de niveau recherche, publiés ou non, émanant des établissements d'enseignement et de recherche français ou étrangers, des laboratoires publics ou privés. 
Pathophysiology of the behavioral variant of frontotemporal lobar degeneration: a study combining MRI and FDG-PET

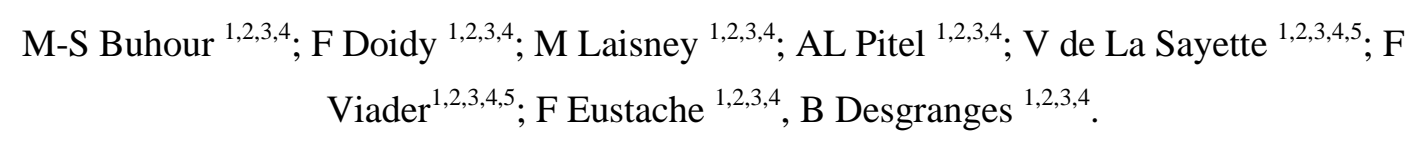

${ }^{1}$ U1077, INSERM, Caen, France

${ }^{2}$ UMR-S1077, University of Caen-Normandy, Caen, France

${ }^{3}$ UMR-S1077, Ecole Pratique des Hautes Etudes, Caen, France

${ }^{4}$ University Hospital, Caen, France

${ }^{5}$ Neurology Department, University Hospital, Caen, France

Corresponding author: B. Desgranges, email: beatrice.desgranges@ unicaen.fr, Tel +33

(0)231568381, Fax : +33(0)2 31470275 


\begin{abstract}
Gray matter (GM) lobar atrophy and glucose hypometabolism are well-described hallmarks of frontotemporal lobar degeneration (FTLD), but the relationships between them are still poorly understood. In this study, we aimed to show the patterns of GM atrophy and hypometabolism in a sample of 15 patients with the behavioral variant of FTLD (bv-FTD), compared to 15 healthy controls, then to provide a direct comparison between GM atrophy and hypometabolism, using a voxel-based method specially designed to statistically compare the two imaging modalities. The participants underwent structural magnetic resonance imaging and ${ }^{18}$ F-fluorodeoxyglucose (FDG) positron emission tomography examinations. First, between-group comparisons of GM volume and metabolism were performed. Then, in the patient group, correlations between regional alterations and direct between-modality voxelwise comparison were performed. Finally, we examined individual patterns of brain abnormalities for each imaging modality and each patient. The observed patterns of GM atrophy and hypometabolism were consistent with previous studies. We found significant voxelwise correlations between changes in GM and FDG uptake, mainly in the frontal cortex, corresponding to the typical profile of alterations in bv-FTD. The direct comparison revealed regional variability in the relationship between hypometabolism and atrophy. This analysis revealed greater atrophy than hypometabolism in the right putamen and amygdala, and left insula and superior temporal gyrus, whereas hypometabolism was more severe than GM atrophy in the left caudate nucleus and anterior cingulate cortex. Finally, GM atrophy affected the right amygdala/hippocampus and left insula in $95 \%$ of the patients. These findings provide evidence for regional variations in the hierarchy of hypometabolism and GM atrophy and the relationships between them, and enhance our understanding of the pathophysiology of bvFTD.
\end{abstract}

Keywords: bv-FTD; structural MRI, FDG-PET; voxel-based Morphometry; individual analysis 


\section{Introduction}

Frontotemporal lobar degeneration (FTLD) is a neurodegenerative disease with three variants: nonfluent primary progressive aphasia, semantic dementia (SD), and the frontal variant of FTLD (bv-FTD). The incidence of FTLD is similar to that of Alzheimer's disease (AD) in 45to 64-year-olds, and bv-FTD represents approximately 75\% of these cases (Mercy, Hodges, Dawson, Barker, \& Brayne, 2008). Patients with bv-FTD show marked changes in behavior and personality (Bathgate, Snowden, Varma, Blackshaw, \& Neary, 2001; Bozeat, Gregory, Ralph, \& Hodges, 2000; Ikeda, Brown, Holland, Fukuhara, \& Hodges, 2002; Nyatsanza et al., 2003; Piguet, 2011; Snowden et al., 2001). A decline in social interpersonal conduct is among the most striking features of bv-FTD: patients may become socially disinhibited, exhibiting facetiousness and inappropriate jocularity. Apathy, reduced empathy, and a complete lack of concern for others are often observed. Impaired insight also translates into a lack of consciousness of mental symptoms, with patients being unaware of the changes in their personality and behavior (Piguet, Hornberger, Mioshi, \& Hodges, 2011). Even though some recent findings have pointed to genuine episodic memory deficits in bv-FTD (Mendez, Shapira, McMurtray, Licht, \& Miller, 2007; Piguet, Hornberger, Shelley, Kipps, \& Hodges, 2009), severe amnesia is still considered to be a neuropsychological exclusion criterion for the diagnosis of bv-FTD (Rascovsky et al., 2011).

Bv-FTD is characterized by predominant lesions in the frontal and/or anterior temporal brain regions of variable distribution (Hodges \& Miller, 2001; Neary et al., 1998; Rascovsky et al., 2007). A number of magnetic resonance imaging (MRI) studies have sought to map in vivo structural brain changes associated with bv-FTD, mostly using statistical parametric mapping (SPM) software, which allows for voxel-by-voxel analysis of the whole brain (voxel-based morphometry, VBM, (Good et al., 2001)). Numerous studies have attempted to investigate the impact of bv-FTD on cerebral gray matter (GM). Some of them had a less than ideal design (e.g., comparison between patients with bv-FTD and a group composed of both healthy individuals and patients with SD (Rosen et al., 2002) or a mixture of patients with bv-FTD and SD (Grossman et al., 2004; Rabinovici et al., 2007; Williams, Nestor, \& Hodges, 2005), making it impossible to say which brain regions were specifically involved in bv-FTD. More recent studies, comparing patients with bv-FTD and healthy agematched controls, have highlighted abnormalities in the frontal dorsomedial, orbital and 
insular cortices, as well as in the striatum and temporal cortex (Boccardi et al., 2003; Couto et al., 2013; Irish, Piguet, Hodges, \& Hornberger, 2014; Lillo et al., 2012; Möller et al., 2015; Perry et al., 2012; Rohrer et al., 2010; Schroeter et al., 2014; Seeley et al., 2008; Whitwell et al., 2010; Zhang et al., 2013)

Metabolic imaging analyses using ${ }^{18}$ fluorodeoxyglucose-PET (FDG-PET) have also been performed in bv-FTD. These investigations revealed metabolic deficits not only in frontal and/or temporal regions (Diehl et al., 2004; Garraux, Salmon, Degueldre, Lemaire, Laureys, et al., 1999; Jeong et al., 2005;Franceschi et al., 2005; Salmon et al., 2003), but also in other brain structures, such as the basal ganglia (Diehl et al., 2004; Franceschi et al., 2005; Garraux, Salmon, Degueldre, Lemaire, Laureys, et al., 1999; Jeong et al., 2005; Salmon et al., 2003), anterior cingulate gyrus (Franceschi et al., 2005; Garraux, Salmon, Degueldre, Lemaire, Laureys, et al., 1999; Ishii et al., 1998), hippocampus (Franceschi et al., 2005; Ishii et al., 1998), and parietal cortex (Diehl-Schmid et al., 2007; Garraux, Salmon, Degueldre, Lemaire, \& Franck, 1999; Ishii et al., 1998; Kipps, Nestor, Fryer, \& Hodges, 2007). These findings have to be interpreted cautiously, as measures of glucose metabolism may be biased in patients with degenerative diseases studied by PET, owing to partial volume effects (PVEs). Despite technological advances, PET continues to suffer from relatively low spatial resolution. As a result, in structures with dimensions similar to the scanner's spatial resolution and bordered by cerebrospinal fluid or WM, the apparent radiotracer concentration is underestimated. PVEs are also particularly marked when the brain tissue is atrophic, as it is in bv-FTD (Quarantelli et al., 2004). While it is essential to correct for PVEs in order to improve spatial resolution, to our knowledge, none of the above-mentioned PET studies did so.

Even though morphological and functional abnormalities seem to concern broadly the same areas, it is important to look more closely for possible differences or similarities in the regions with brain volume loss and hypometabolism, if we want to improve our understanding of the disease's pathophysiology. No study has yet attempted to do this in the same group of patients. Some studies have combined anatomical MRI and FDG-PET within the same sample of patients, but not to probe the relationship between those two abnormalities (Frisch et al., 2013; Kanda et al., 2008; Kipps, Hodges, Fryer, \& Nestor, 2009; Woost et al., 2013). Moreover, most previous imaging investigations have involved group comparisons between bv-FTD patients and controls, with only one examining individual patterns of metabolic 
abnormalities (Salmon et al., 2003). This study identified the ventromedial frontopolar cortex as the one region to be affected in every single patient in the sample.

The first goal of the present study was thus to provide a comprehensive assessment of GM volumes, as well as glucose metabolism, in a group of patients with bv-FTD, adopting a voxel-based approach. After assessing each of them separately, we carried out voxelwise correlations between GM atrophy and hypometabolism, using biological parametric mapping (BPM) software. This method allowed us to improve our understanding of the disease's pathophysiological mechanisms by probing neuroimaging data in both the functional and structural imaging modalities. We then used a specific processing technique to carry out direct voxelwise comparisons of the degree of local GM atrophy and hypometabolism, using a method that had previously been developed in our laboratory and successfully implemented in early AD (Chételat et al., 2008; La Joie et al., 2012) and alcoholism (Pitel et al., 2009). The second goal of the present study was to identify the brain regions affected by GM atrophy or hypometabolism in each of the patients in our sample, looking for heterogeneity in the individual patterns of brain abnormalities. We conducted separate analyses of the MRI and FDG-PET data.

\section{Materials and Methods}

Participants

We included 15 patients with probable bv-FTD (10 men and 5 women, mean age $=67$ \pm 8.2 years) in the present study, selected according to the revised criteria established by Rascovsky et al. (Rascovsky et al., 2011). These patients underwent a neurological examination and a standard neuropsychological assessment (including the Free and Cued Selective Reminding Test (Eustache, Desgranges, Giffard, de la Sayette, \& Baron, 2001). The data of some of these patients had already been included in previous publications (Laisney et al., 2009; Matuszewski et al., 2006; Piolino et al., 2007). The diagnosis of bv-FTD was confirmed by following the patients up for several years. To analyze the neuroimaging data, we included a group of 15 healthy controls (6 men and 9 women), matched with the patient group for age (mean age $=66.5 \pm 8.3$ years), sex and years of education. The participants had a minimum level of education equivalent to the French primary school certificate, obtained after 8 years of primary education. None of the participants had a history of alcoholism or psychiatric or neurological problems (head injury, trauma, epilepsy, depression, etc.). All the 
participants gave their written informed consent prior to their inclusion in the study, which was approved by the local ethics committee.

Imaging data acquisition

Each participant underwent a high-resolution, T1 weighted MRI scan, consisting of a set of 128 adjacent axial cuts parallel to the AC-PC line with a slice thickness of $1.5 \mathrm{~mm}$ and a 0.94 x 0.94-mm pixel size, using a spoiled gradient echo sequence $(\mathrm{TR}=10.3 \mathrm{~ms}$, TE $=2.1$ $\mathrm{ms}, \mathrm{FOV}=240 \times 180 \mathrm{~mm}^{2}$ matrix $\left.=256 \times 192\right)$. All the MRI datasets were acquired on the same scanner (1.5T Signa Advantage Echospeed; General Electric) using the same acquisition protocol.

Participants also underwent a PET scan within days of the MRI examination. Data were acquired using an ECAT Exact HR+ PET device with an isotropic resolution of $4.6 \times 4.2$ x $4.2 \mathrm{~mm}$ and axial field of view of $158 \mathrm{~mm}$. Participants were fasted for at least 4 hours before the scan. To minimize anxiety, the PET procedure was explained in detail beforehand. The head was positioned on a headrest relative to the canthomeatal line and gently restrained with straps. ${ }^{18}$ FDG uptake was measured in the resting condition with eyes closed, in a quiet and dark environment. A catheter was inserted into a vein of the arm to inject the radiotracer. Following ${ }^{68}$ gallium transmission scans, $3-5 \mathrm{mCi}$ of ${ }^{18} \mathrm{FDG}$ were injected as a bolus at Time 0 and a 10-min data acquisition period started $50 \mathrm{~min}$ post injection. Sixty-three planes were acquired with no septa (3D acquisition), using a voxel size of $2.2 \times 2.2 \times 2.43 \mathrm{~mm}$ (x, y, z). During PET data acquisition, head motion was continuously monitored with, and whenever necessary corrected according to, laser beams projected onto ink marks on the forehead.

\section{Image processing}

The data processing procedure was especially designed to compare morphological and metabolic data, as described in detail elsewhere (Chételat et al., 2008; Pitel et al., 2009) and illustrated in Figure 1. The MRI datasets were analyzed using VBM in SPM5, as recommended by Good et al. This procedure included segmentation, spatial normalization of the original raw MRI data using the MNI template of SPM5 as a prior, and modulation. Finally, the registered MRI data were smoothed (see below). The procedure yielded maps of local GM volume corrected for brain size. 
The PET data were first corrected for PVEs arising from both cerebrospinal fluid and white matter, using the modified Müller-Gärtner method (Müller-Gärtner et al., 1992; Rousset, Ma, \& Evans, 1998) described in detail in (Quarantelli et al., 2004). All the image-processing steps for PVE correction were carried out using PMOD software (PMOD Technologies Ltd., Adliswil, Switzerland). The PVE-corrected PET data were then coregistered onto their corresponding MRI scans and normalized using the deformation parameters defined by the VBM procedure described above. The resulting images were scaled using the metabolism of the cerebellum as a reference. This meant that the PET images were divided by their mean cerebellar FDG uptake value to control for individual variations in the overall PET value (Mevel et al., 2007). The cerebellum was selected as a reference because it had the best preserved FDG uptake value in our sample of patients relative to controls (data not shown). Finally, the corrected and spatially normalized PET data were smoothed.

For the between-group comparisons, and in order to blur individual variations in gyral anatomy and increase the signal-to-noise ratio, the registered MRI data were smoothed using a 12-mm Gaussian kernel, and the PET datasets were smoothed using a 14-mm Gaussian kernel. For the direct comparison between structural and metabolic GM abnormalities, a different Gaussian kernel was applied to the registered unsmoothed MRI datasets, to compensate for the difference in the original spatial resolution between the two modalities (Chételat et al., 2008; Villain et al., 2008). A 14.6-mm Gaussian kernel was used for the MRI GM data, resulting in an effective smoothness identical to that of the PET images smoothed at $14 \mathrm{~mm}$.

The resulting MRI and PET datasets were masked to include only GM voxels of interest and prevent contamination of the analysis by misclassified voxels as much as possible (see Villain et al. (2008) for details). Briefly, we created mean images of GM and white matter partitions for the whole sample ( $N=30$ images). The white matter mask was obtained by thresholding the mean white matter image at a value of 0.4. A preliminary GM mask was first created by thresholding the mean GM image at a value of 0.3 . The final GM mask was obtained by subtracting the white matter mask from the preliminary GM mask. The resulting binary GM mask was applied to both the MRI GM and PET datasets.

Our main objective was to perform a direct whole brain comparison of the degrees and location of atrophy and hypometabolism within the bv-FTD group, using a method especially designed for this purpose. Atrophy and hypometabolism do not have the same units, making 
their direct comparison impossible. Therefore, the smoothed and masked GM and PET images were used to create $\mathrm{z}$-score maps ( $\left.\frac{\text { patient individual value-control mean }}{\text { control standard deviation }}\right)$ for each voxel of each patient and for each modality.

\section{Statistical analysis}

Between-group comparisons of GM volumes and metabolism

First, we compared the two groups within each imaging modality to obtain maps of significant GM atrophy, as well as hypometabolism in the patients with bv-FTD compared with controls. Two independent analyses were performed on the MRI and PET data of the two groups (bv-FTD and controls), using the SPM5 two-sample $t$ test routine. For GM volumes, results were deemed to be significant at the familywise error (FWE) threshold of $p=0.05$, with a minimum cluster size of 160 voxels $\left(160 \mathrm{~mm}^{3}\right)$. Concerning the PET data, results were deemed to be significant at the FWE threshold of $p=0.05$, with a minimum cluster size of 20 voxels $\left(160 \mathrm{~mm}^{3}\right)$. In addition, we also reported the results of the between group comparisons using a less restrictive threshold of $p_{\text {uncorrected }}<0.001$ in order to have a global view of the pathology.

Correlation between regional alterations in patients

To assess the relationship between regional GM atrophy and hypometabolism, $z$-score maps were entered pairwise in a voxelwise correlation analysis using the BPM toolbox implemented in SPM, which is especially designed to analyze brain images in different modalities (Casanova et al., 2007). This analysis shows all the voxels that evolve in the same manner. More specifically, the voxels presenting a correlation between GM atrophy and glucose hypometabolism are highlighted. Results were deemed to be significant below an uncorrected threshold of $p=0.001$, with a minimum cluster size of 160 voxels.

Comparisons between structural and metabolic abnormalities in patients

Direct comparisons between the degree of structural and metabolic abnormalities were only performed for voxels with significant GM atrophy or hypometabolism. For this purpose, we averaged the GM volume and FDG uptake $z$-score maps for all participants, to obtain a mean $z$-score map for GM volume and a mean $z$-score map for FDG uptake. We then thresholded these two maps by only including voxels with a mean MRI or PET $z$ score $<-1.77$ 
(corresponding to the $t$ value for one-tailed $p=0.05$ with 13 degrees of freedom). These two new masked images were applied to all the patients' $z$-score maps. The individual masked atrophy and hypometabolism $z$-score maps were finally entered in an SPM one-tailed $t$ test analysis, with one group (bv-FTD) and two images per participant. The two contrasts ( $z$ PET $<z$ MRI and $z$ MRI $<z$ PET) yielded statistical maps reflecting any predominance of atrophy over hypometabolism and vice versa. Results were deemed to be significant below the FWE threshold of $p=0.05$, with a minimum cluster size of 100 voxels for both contrasts.

Variability of the individual patterns of GM atrophy and hypometabolism

To examine between-participants variability in the patterns of GM atrophy and hypometabolism in the bv-FTD group, we first thresholded each individual GM and PET $z$ score map at -1.77 to obtain a value of 1 for voxels in each patient's map with significant atrophy or hypometabolism, and a value of 0 everywhere else. We then summed the 15 individual binary images for GM and PET. The two resulting maps reflected the frequency in each voxel of significant GM atrophy or hypometabolism in our sample, ranging from 0 (i.e., present in none of the patients) to 15 (i.e., present in all the patients).

\section{RESULTS}

Between-group comparisons

GM volume loss was located within the frontal lobe (right ventrolateral prefrontal cortex, superior frontal gyrus and rectus gyrus on both sides, right orbitofrontal gyrus and left superior medial frontal cortex), left insula, both caudate nuclei, right thalamus, right anterior cingulate cortex, temporal lobe (right superior temporal gyus, left inferior temporal gyrus), and parietal lobe (right supramarginal gyrus and right angular gyrus) (Table 1 and Fig. 2).

Significant hypometabolism was present in the caudate nuclei, frontal cortex (right inferior orbital gyrus, right middle orbital gyrus, right supplementary motor area and superior frontal gyrus and medial superior frontal gyrus on both sides), cingulate cortex (middle cingulate cortex on both sides, left anterior cingulate cortex) and right inferior temporal gyrus (Table 2 and Fig. 2). 


\section{Voxelwise correlations between GM atrophy and hypometabolism}

The pairwise intermodality correlation analyses revealed that significant correlations between GM atrophy and hypometabolism in the patient group mainly involved 1) the frontal cortex, including the superior medial frontal cortex on both sides, right middle frontal gyrus and right inferior frontal cortex, 2) the right temporal pole, and 3) the left anterior cingulate cortex (Fig.3).

\section{Within-group comparisons between morphological and metabolic abnormalities}

The GM atrophy > hypometabolism contrast was significant in the right putamen and amygdala, as well as the left insula and superior temporal gyrus (Fig.4). The reverse contrast (hypometabolism > GM atrophy) was only significant in the left caudate and anterior cingulate cortex.

\section{Variability of the individual patterns of GM atrophy and hypometabolism}

We sought to identify brain regions that were consistently atrophied (for GM and WM) or hypometabolic in our patients. GM volume loss was found in the right amygdala, right hippocampus and left insula of 14/15 (95\%) of them. No brain region consistently presenting glucose hypometabolism was observed in the patients. However, in 12/15 (85\%) of patients, we observed glucose hypometabolism in both caudate nuclei and right orbital frontal and t superior frontal gyri. (Table 3).

\section{DisCUSSION}

To our knowledge, this is the first neuroimaging study to have closely examined the matches and mismatches between the profiles of GM volume loss and hypometabolism in a single group of 15 patients with bv-FTD, compared with a group of 15 strictly matched controls. We also sought to identify the brain regions affected by GM atrophy or hypometabolism in each individual patient. The patterns and magnitude of these brain abnormalities and the relationships between them were assessed voxelwise. 
We found 1) marked GM atrophy in the frontal lobe, insula and caudate nuclei and, to a lesser extent, the parietal and temporal cortices, and 2) glucose hypometabolism mainly in the caudate nuclei and several parts of the frontal cortex the superior medial frontal cortex and superior frontal gyrus on both sides, and right middle frontal gyrus). We also found correlations between GM atrophy and hypometabolism within a large proportion of the prefrontal regions. We further observed that GM atrophy predominated over hypometabolism in the right putamen and amygdala, as well as in the left insula and superior temporal gyrus, while hypometabolism predominated over GM atrophy in the left caudate nucleus and anterior cingulate cortex. Finally, we found that GM atrophy affected the right amygdala/hippocampus and left insula in $95 \%$ of patients with bv-FTD, while the caudate nuclei and prefrontal cortex were hypometabolic in $85 \%$ of patients.

Our analyses of GM volume and metabolism, considered separately, highlighted the involvement of a large frontotemporal-insular network, as well as the caudate nuclei, thalamus and anterior cingulate cortex, in accordance with the literature (see introduction, Schroeter et al., 2014). Abnormalities in these structures are thought to be responsible for the main clinical features of this pathology (e.g., apathy, disinhibition, dietary changes, emotion and reward processing deficit, loss of empathy and dysexecutive syndrome; see, for instance Schroeter et al., 2011).

The voxelwise correlations between GM volume deficits and changes in FDG uptake, established here for the first time in bv-FTD, showed that atrophy and hypometabolism were correlated within the dorsolateral (to a greater extent on the right side) and median frontal cortices. This voxelwise correlation found within the prefrontal cortex may indicate that changes in this area share common mechanisms, and more specifically that the loss of GM volume is primarily dependent on neuronal death, with neither compensatory nor disconnection mechanisms at work. Interestingly, the dorsolateral and median frontal areas where metabolism and brain volume were correlated appear to be highly clinically significant in the setting of bv-FTD, just as the temporoparietal cortex is in AD, as shown by La Joie et al. (La Joie et al., 2012) using a similar methodology. This result is also in accordance with Shimizu et al. (Shimizu et al., 2010), who used perfusion imaging and structural MRI. These authors revealed concordant GM atrophy and hypoperfusion changes in the right prefrontal cortex and both sides of the medial frontal lobe. 
In an attempt to provide a more detailed description of brain changes in our group of patients with bv-FTD, we undertook a direct comparison between both modalities, namely anatomical MRI and FDG-PET. Analyses revealed that cortical atrophy predominated over hypometabolism in the right putamen and amygdala, as well as in the left insula and superior temporal gyrus. Frisch et al., (2013) found that GM atrophy was located in similar regions as hypometabolism, as well as in the left hippocampus and the thalamus. These authors hypothesized that GM atrophy and cerebral glucose hypometabolism can be relatively independent of each other. With our specific methodology, allowing the direct comparison of MRI and FDG-PET data, we were able to confirm this hypothesis.

A discrepancy between brain volume and metabolism measurements had previously been found by Shimizu et al., (2010) in a series of 28 patients, and confirmed by Schroeter et al., (2014) in their meta-analysis of more than 400 cases, but its relevance to the disease's pathophysiology remains to be elucidated. It seems surprising that atrophy can exceed hypometabolism, as GM loss is usually synonymous with neuronal/synaptic loss, so we would not normally expect to see atrophy exceeding hypometabolism. However, as Shimizu et al. suggested, the loss of brain cells other than neurons may result in atrophy without regional hypometabolism. This is supported by two neuropathological studies showing that the earliest cellular changes in FTLD occur in astrocytes (Broe et al., 2003; Kersaitis, Halliday, \& Kril, 2004). The finding of less hypometabolism than atrophy also suggests that compensatory mechanisms are at work in these structures, helping to maintain a moderately high metabolic level relative to structural alterations-a hypothesis previously developed by Chetelat et al., (2003) and La Joie et al., (2012) for AD.

We also found the reverse dissociation, namely greater hypometabolism than atrophy, in the left caudate nucleus and anterior cingulate cortex. This points to a genuine functional alteration (metabolic, chemical or molecular) over and above neuronal loss, heightening the functional consequence of local atrophy. This phenomenon has also been found in a recent meta-analysis (Schroeter et al., 2014) covering a total of 417 patients with bv-FTD where 20 studies measured GM atrophy and 11 others that examined hypometabolism. Superimposition of the corresponding maps (though with no statistical comparisons) and visual analysis of the two imaging methods revealed that hypometabolism exceeded atrophy in the gyrus rectus and middle thalamus on both sides, and in the left posterior inferior frontal sulcus. In AD, some authors also found greater hypometabolism than GM atrophy and putatively considered it to 
be a remote effect of atrophy on metabolism though the functional disruption of connected areas (Chételat et al., 2008).

This is suggestive of diaschisis, namely a decrease in the metabolic activity of neurons that are anatomically or functionally connected to the damaged area. The GM atrophy found in the medial temporal and frontal lobes of our patients may thus correspond to neuronal loss that remotely affected the metabolism of the anterior cingulate cortex and caudate nucleus, respectively. This situation may be limited in time, as disconnected neurons eventually die as a result of transsynaptic degeneration, giving rise to different patterns of brain volume and metabolic impairment, depending on the stage of the disease.

\section{Interindividual variability in the patterns of GM atrophy and hypometabolism}

When we analyzed the variability in the structural and metabolic brain abnormalities in our sample of 15 patients with bv-FTD, we found that 12 of them had cerebral glucose hypometabolism within the frontal lobe (right orbitofrontal gyrus and right superior frontal gyrus) and both caudate nuclei.

Regarding GM volume, we observed atrophy in the right amygdala and hippocampus, as well as the left insula, in 14 of the patients. Atrophy of the amygdala has already been observed in several volumetric studies (Boccardi et al., 2003; Irish, Piguet, Hodges, \& Hornberger, 2014; Möller et al., 2015; Seeley et al., 2008). The amygdala's involvement has been confirmed by neuropathological studies showing that this structure degenerates at an early stage in bv-FTD (Kril \& Halliday, 2004; Kril, Macdonald, Patel, Png, \& Halliday, 2005). The insula has also already been found to be atrophic in several VBM (Boccardi et al., 2005; Lillo et al., 2012; Perry et al., 2012; Zhang et al., 2013) and cortical thickness studies (Richards et al., 2009). Furthermore, our finding is in line with neuropathological studies suggesting that the insula is one of the sites where bv-FTD begins (Broe et al., 2003; Kril et al., 2005).

Regarding the involvement of the hippocampus, our result fits several recent studies that found that this structure was atrophied in bv-FTD (de Souza et al., 2013; Lindberg et al., 2012; Muñoz-Ruiz et al., 2012; Tan, Wong, Hodges, Halliday, \& Hornberger, 2013). These studies featured group analyses; whereas we showed that 14/15 patients with bv-FTD had hippocampal volume deficits. Moreover, it has been increasingly recognized that bv-FTD patients can also exhibit amnesia in addition to their frontal behavioral disturbances (Bertoux 
et al., 2014; Hou, Miller, \& Kramer, 2005; Irish et al., 2011; Matuszewski et al., 2006; Pasquier, Grymonprez, Lebert, \& Van der Linden, 2001; Pijnenburg, Gillissen, Jonker, \& Scheltens, 2004; Piolino et al., 2007), even at initial stage. In addition, Hodges et al. (Hodges et al., 2004) showed that 5 of 26 patients with pathologically proven FTLD exhibited marked amnesia. Graham et al., (2005) made the same observation when they examined the records of a neuropathological series of 71 patients with bv-FTD

GM atrophy of the hippocampus is not, however, specific to this pathology. It has also been found in SD (e.g., Desgranges et al., (2007)), as well as in AD, of course (La Joie et al., 2012; Villain et al., 2008). La Joie et al., (2014) even identified the hippocampus as the main intersection between the networks targeted by $\mathrm{AD}$ and SD. According to these authors, regions within the anterior temporal system are connected to the anterior hippocampus (impaired in SD), whereas the posterior medial system is primarily linked to the posterior hippocampus (impaired in AD). In the case of bv-FTD, the impairment may concern the hippocampus and its connection to other brain structures, such as the frontal cortex or the anterior cingulate cortex, which may account for the cognitive pattern specific to this pathology. Further studies are needed to explore the clinical impact of hippocampal atrophy in bv-FTD.

Several limitations in our study deserve to be mentioned. First, the patients were diagnosed clinically, with no post mortem confirmation of bv-FTD, and above all we had no information about the type of molecular pathology. Although bv-FTD can occur in the case of either tau, TDP-43 or FUS protein deposits (Josephs et al., 2008), these proteinopathies are not characterized by specific neuroimaging patterns (Whitwell \& Josephs, 2011). It is important to note that the patients with bv-FTD were followed up over several years, undergoing regular neuropsychological assessments that confirmed their diagnosis. Second, the small number of patients with bv-FTD (15) limited the power of the final analysis, which was designed to probe the variability of the morphological and metabolic brain abnormalities. It is, however, challenging to find larger numbers of carefully selected patients with both MRI and PET data. 


\section{CONCLUSION}

Taken together, our results highlighted structural and metabolic changes in the brains of patients with bv-FTD. Frontal regions cannot be regarded as the only brain target of bvFTD. Furthermore, there is a relative overlap of the profiles of metabolic and structural change. However, we also found that atrophy was greater than hypometabolism in some brain regions, suggesting that cellular changes in bv-FTD may occur in brain cells other than neurons. By contrast, we also found that hypometabolism was more severe than atrophy in some brain areas-a finding that can be explained by a disconnection mechanism. Finally, GM volume loss was found in 14/15 of patients with bv-FTD, located in the right amygdala and right hippocampus, as well as in the left insula-abnormalities that could be regarded as potential brain biomarkers for bv-FTD. 


\section{COMPLIANCE WITH ETHICAL STANDARDS}

Conflict of Interests: Author Marie-Sonia BUHOUR declares that she has no conflict of interest. Author Franck Doidy declares he has no conflict of interest. Author Mickaël Laisney declares he has no conflict of interest. Author Anne-Lise Pitel declares she has no conflict of interest. Author Vincent de la Sayette declares he has no conflict of interest. Author Fausto Viader declares he has no conflict of interest. Author Francis Eustache declares he has no conflict of interest. Author Béatrice Desgranges declares she has no conflict of interest.

Ethical approval: All procedures performed in studies involving human participants were in accordance with the ethical standards of the institutional and/or national research committee and with the 1964 Helsinki declaration and its later amendments or comparable ethical standards.

Informed consent: Informed consent was obtained from all individual participants included in the study.

\section{REFERENCES}

Bathgate, D., Snowden, J. S., Varma, A., Blackshaw, A., \& Neary, D. (2001). Behaviour in frontotemporal dementia, Alzheimer's disease and vascular dementia, 367-378. Retrieved from http://www.ncbi.nlm.nih.gov/pubmed/11421849

Bertoux, M., de Souza, L. C., Corlier, F., Lamari, F., Bottlaender, M., Dubois, B., \& Sarazin, M. (2014). Two distinct amnesic profiles in behavioral variant frontotemporal dementia. Biological Psychiatry, 75(7), 582-588. http://doi.org/10.1016/j.biopsych.2013.08.017

Boccardi, M., Laakso, M. P., Bresciani, L., Galluzzi, S., Geroldi, C., Beltramello, A., ... Frisoni, G. B. (2003). The MRI pattern of frontal and temporal brain atrophy in frontotemporal dementia. Neurobiology of Aging, 24(1), 95-103. Retrieved from http://www.ncbi.nlm.nih.gov/pubmed/12493555

Boccardi, M., Sabattoli, F., Laakso, M. P., Testa, C., Rossi, R., Beltramello, A., ... Frisoni, G. B. (2005). Frontotemporal dementia as a neural system disease. Neurobiology of Aging, 26(1), 37-44. http://doi.org/10.1016/j.neurobiolaging.2004.02.019

Bozeat, S., Gregory, C. A., Ralph, M. A., \& Hodges, J. R. (2000). Which neuropsychiatric and behavioural features distinguish frontal and temporal variants of frontotemporal dementia from Alzheimer's disease? Journal of Neurology, Neurosurgery, and Psychiatry, 69(2), 178-186. $\quad$ Retrieved from http://www.ncbi.nlm.nih.gov/pubmed/10896690

Broe, M., Hodges, J. R., Schofield, E., Shepherd, C. E., Kril, J. J., \& Halliday, G. M. (2003). Staging disease severity in pathologically confirmed cases of frontotemporal dementia. Neurology, $60(6)$ 1005-1011. 
http://www.ncbi.nlm.nih.gov/pubmed/12654969

Casanova, R., Srikanth, R., Baer, A., Laurienti, P. J., Burdette, J. H., Hayasaka, S., ... Maldjian, J. A. (2007). Biological parametric mapping: A statistical toolbox for multimodality brain image analysis. NeuroImage, 34(1), 137-143. http://doi.org/10.1016/j.neuroimage.2006.09.011

Chételat, G., Desgranges, B., de La Sayette, V., Viader, F., Berkouk, K., Landeau, B., ... Eustache, F. (2003). Dissociating atrophy and hypometabolism impact on episodic memory in mild cognitive impairment. Brain: A Journal of Neurology, 126(Pt 9), 19551967. http://doi.org/10.1093/brain/awg196

Chételat, G., Desgranges, B., Landeau, B., Mézenge, F., Poline, J. B., de La Sayette, V., ... Baron, J.-C. (2008). Direct voxel-based comparison between grey matter hypometabolism and atrophy in Alzheimer's disease. Brain: A Journal of Neurology, 131(Pt 1), 60-71. http://doi.org/10.1093/brain/awm288

Couto, B., Manes, F., Montañés, P., Matallana, D., Reyes, P., Velasquez, M., ... Ibáñez, A. (2013). Structural neuroimaging of social cognition in progressive non-fluent aphasia and behavioral variant of frontotemporal dementia. Frontiers in Human Neuroscience, 7 , 467. http://doi.org/10.3389/fnhum.2013.00467

de Souza, L. C., Chupin, M., Bertoux, M., Lehéricy, S., Dubois, B., Lamari, F., ... Sarazin, M. (2013). Is hippocampal volume a good marker to differentiate Alzheimer's disease from frontotemporal dementia? Journal of Alzheimer's Disease: JAD, 36(1), 57-66. http://doi.org/10.3233/JAD-122293

Desgranges, B., Matuszewski, V., Piolino, P., Chételat, G., Mézenge, F., Landeau, B., ... Eustache, F. (2007). Anatomical and functional alterations in semantic dementia: a voxel-based MRI and PET study. Neurobiology of Aging, 28(12), 1904-1913. http://doi.org/10.1016/j.neurobiolaging.2006.08.006

Diehl, J., Grimmer, T., Drzezga, A., Riemenschneider, M., Förstl, H., \& Kurz, A. (2004). Cerebral metabolic patterns at early stages of frontotemporal dementia and semantic dementia. A PET study. Neurobiology of Aging, 25(8), 1051-1056. http://doi.org/10.1016/j.neurobiolaging.2003.10.007

Diehl-Schmid, J., Grimmer, T., Drzezga, A., Bornschein, S., Riemenschneider, M., Förstl, H., ... Kurz, A. (2007). Decline of cerebral glucose metabolism in frontotemporal dementia: a longitudinal 18F-FDG-PET-study. Neurobiology of Aging, 28(1), 42-50. http://doi.org/10.1016/j.neurobiolaging.2005.11.002

Eustache, F., Desgranges, B., Giffard, B., de La Sayette, V., \& Baron, J. C. (2001). Entorhinal cortex disruption causes memory deficit in early Alzheimer's disease as shown by PET. Neuroreport, 12(4), 683-685. Retrieved from http://www.ncbi.nlm.nih.gov/pubmed/11277563

Franceschi, M., Anchisi, D., Pelati, O., Zuffi, M., Matarrese, M., Moresco, R. M., .. Perani, D. (2005). Glucose metabolism and serotonin receptors in the frontotemporal lobe degeneration. Annals of Neurology, 57(2), 216-225. http://doi.org/10.1002/ana.20365

Frisch, S., Dukart, J., Vogt, B., Horstmann, A., Becker, G., Villringer, A., ... Schroeter, M. L. (2013). Dissociating memory networks in early Alzheimer's disease and frontotemporal lobar degeneration - a combined study of hypometabolism and atrophy. PloS One, 8(2), e55251. http://doi.org/10.1371/journal.pone.0055251 
Garraux, G., Salmon, E., Degueldre, C., Lemaire, C., \& Franck, G. (1999). Medial temporal lobe metabolic impairment in dementia associated with motor neuron disease. Journal of the Neurological Sciences, 168(2), 145-150. Retrieved from http://www.ncbi.nlm.nih.gov/pubmed/10526199

Garraux, G., Salmon, E., Degueldre, C., Lemaire, C., Laureys, S., \& Franck, G. (1999). Comparison of impaired subcortico-frontal metabolic networks in normal aging, subcortico-frontal dementia, and cortical frontal dementia. NeuroImage, 10(2), 149-162. http://doi.org/10.1006/nimg.1999.0463

Good, C. D., Johnsrude, I. S., Ashburner, J., Henson, R. N., Friston, K. J., \& Frackowiak, R. S. (2001). A voxel-based morphometric study of ageing in 465 normal adult human brains. NeuroImage, 14(1 Pt 1), 21-36. http://doi.org/10.1006/nimg.2001.0786

Graham, A., Davies, R., Xuereb, J., Halliday, G., Kril, J., Creasey, H., ... Hodges, J. (2005). Pathologically proven frontotemporal dementia presenting with severe amnesia. Brain: A Journal of Neurology, 128(Pt 3), 597-605. http://doi.org/10.1093/brain/awh348

Grossman, M., McMillan, C., Moore, P., Ding, L., Glosser, G., Work, M., \& Gee, J. (2004). What's in a name: voxel-based morphometric analyses of MRI and naming difficulty in Alzheimer's disease, frontotemporal dementia and corticobasal degeneration. Brain: A Journal of Neurology, 127(Pt 3), 628-649. http://doi.org/10.1093/brain/awh075

Hodges, J. R., Davies, R. R., Xuereb, J. H., Casey, B., Broe, M., Bak, T. H., ... Halliday, G. M. (2004). Clinicopathological correlates in frontotemporal dementia. Annals of Neurology, 56(3), 399-406. http://doi.org/10.1002/ana.20203

Hodges, J. R., \& Miller, B. (2001). The classification, genetics and neuropathology of frontotemporal dementia. Introduction to the special topic papers: Part I. Neurocase, 7(1), 31-35. http://doi.org/10.1093/neucas/7.1.31

Hou, C. E., Miller, B. L., \& Kramer, J. H. (2005). Patterns of autobiographical memory loss in dementia. International Journal of Geriatric Psychiatry, 20(9), 809-815. http://doi.org/10.1002/gps.1361

Ikeda, M., Brown, J., Holland, A. J., Fukuhara, R., \& Hodges, J. R. (2002). Changes in appetite, food preference, and eating habits in frontotemporal dementia and Alzheimer's disease. Journal of Neurology, Neurosurgery, and Psychiatry, 73(4), 371-376.

Irish, M., Hornberger, M., Lah, S., Miller, L., Pengas, G., Nestor, P. J., ... Piguet, O. (2011). Profiles of recent autobiographical memory retrieval in semantic dementia, behaviouralvariant frontotemporal dementia, and Alzheimer's disease. Neuropsychologia, 49(9), 2694-2702. http://doi.org/10.1016/j.neuropsychologia.2011.05.017

Irish, M., Piguet, O., Hodges, J. R., \& Hornberger, M. (2014). Common and unique gray matter correlates of episodic memory dysfunction in frontotemporal dementia and Alzheimer's disease. Human Brain Mapping, 35(4), 1422-1435. http://doi.org/10.1002/hbm.22263

Ishii, K., Sakamoto, S., Sasaki, M., Kitagaki, H., Yamaji, S., Hashimoto, M., ... Mori, E. (1998). Cerebral glucose metabolism in patients with frontotemporal dementia. Journal of Nuclear Medicine: Official Publication, Society of Nuclear Medicine, 39(11), 18751878. Retrieved from http://www.ncbi.nlm.nih.gov/pubmed/9829574

Jeong, Y., Cho, S. S., Park, J. M., Kang, S. J., Lee, J. S., Kang, E., ... Kim, S. E. (2005). 18FFDG PET findings in frontotemporal dementia: an SPM analysis of 29 patients. Journal 
of Nuclear Medicine: Official Publication, Society of Nuclear Medicine, 46(2), 233-239. Retrieved from http://www.ncbi.nlm.nih.gov/pubmed/15695781

Josephs, K. A., Lin, W.-L., Ahmed, Z., Stroh, D. A., Graff-Radford, N. R., \& Dickson, D. W. (2008). Frontotemporal lobar degeneration with ubiquitin-positive, but TDP-43-negative inclusions. Acta Neuropathologica, 116(2), 159-167. http://doi.org/10.1007/s00401-0080397-8

Kanda, T., Ishii, K., Uemura, T., Miyamoto, N., Yoshikawa, T., Kono, A. K., \& Mori, E. (2008). Comparison of grey matter and metabolic reductions in frontotemporal dementia using FDG-PET and voxel-based morphometric MR studies. European Journal of Nuclear Medicine and Molecular Imaging, 35(12), 2227-2234. http://doi.org/10.1007/s00259-008-0871-5

Kersaitis, C., Halliday, G. M., \& Kril, J. J. (2004). Regional and cellular pathology in frontotemporal dementia: relationship to stage of disease in cases with and without Pick bodies. Acta Neuropathologica, 108(6), 515-523. http://doi.org/10.1007/s00401-0040917-0

Kipps, C. M., Hodges, J. R., Fryer, T. D., \& Nestor, P. J. (2009). Combined magnetic resonance imaging and positron emission tomography brain imaging in behavioural variant frontotemporal degeneration: refining the clinical phenotype. Brain: A Journal of Neurology, 132(Pt 9), 2566-2578. http://doi.org/10.1093/brain/awp077

Kipps, C. M., Nestor, P. J., Fryer, T. D., \& Hodges, J. R. (2007). Behavioural variant frontotemporal dementia: not all it seems? Neurocase, 13(4), 237-247.

Kril, J. J., \& Halliday, G. M. (2004). Clinicopathological staging of frontotemporal dementia severity: correlation with regional atrophy. Dementia and Geriatric Cognitive Disorders, 17(4), 311-315. http://doi.org/10.1159/000077161

Kril, J. J., Macdonald, V., Patel, S., Png, F., \& Halliday, G. M. (2005). Distribution of brain atrophy in behavioral variant frontotemporal dementia, 83-90. Retrieved from http://www.ncbi.nlm.nih.gov/pubmed/15850587

La Joie, R., Landeau, B., Perrotin, A., Bejanin, A., Egret, S., Pélerin, A., ... Chételat, G. (2014). Intrinsic connectivity identifies the hippocampus as a main crossroad between Alzheimer's and semantic dementia-targeted networks. Neuron, 81(6), 1417-1428. http://doi.org/10.1016/j.neuron.2014.01.026

La Joie, R., Perrotin, A., Barré, L., Hommet, C., Mézenge, F., Ibazizene, M., ... Chételat, G. (2012). Region-specific hierarchy between atrophy, hypometabolism, and $\beta$-amyloid (A $\beta$ ) load in Alzheimer's disease dementia. The Journal of Neuroscience: The Official Journal of the Society for Neuroscience, 32(46), 16265-16273. http://doi.org/10.1523/JNEUROSCI.2170-12.2012

Laisney, M., Matuszewski, V., Mézenge, F., Belliard, S., de La Sayette, V., Eustache, F., \& Desgranges, B. (2009). The underlying mechanisms of verbal fluency deficit in frontotemporal dementia and semantic dementia. Journal of Neurology, 256(7), 10831094. http://doi.org/10.1007/s00415-009-5073-y

Lillo, P., Mioshi, E., Burrell, J. R., Kiernan, M. C., Hodges, J. R., \& Hornberger, M. (2012). Grey and white matter changes across the amyotrophic lateral sclerosis-frontotemporal $\begin{array}{lllll}\text { dementia } & \text { continuum. } & \text { One, } & \text { 7(8), } & \text { 43993. }\end{array}$ http://doi.org/10.1371/journal.pone.0043993 
Lindberg, O., Walterfang, M., Looi, J. C. L., Malykhin, N., Ostberg, P., Zandbelt, B., ... Wahlund, L.-O. (2012). Hippocampal shape analysis in Alzheimer's disease and frontotemporal lobar degeneration subtypes. Journal of Alzheimer's Disease: JAD, 30(2), 355-365. http://doi.org/10.3233/JAD-2012-112210

Matuszewski, V., Piolino, P., de La Sayette, V., Lalevée, C., Pélerin, A., Dupuy, B., ... Desgranges, B. (2006). Retrieval mechanisms for autobiographical memories: insights from the frontal variant of frontotemporal dementia. Neuropsychologia, 44(12), 23862397. http://doi.org/10.1016/j.neuropsychologia.2006.04.031

Mendez MF, Shapira JS, McMurtray A, Licht E, \& Miller BL. (2007). Accuracy of the clinical evaluation for frontotemporal dementia. Archives of Neurology, 64(6), 830-835. http://doi.org/10.1001/archneur.64.6.830

Mercy, L., Hodges, J. R., Dawson, K., Barker, R. A., \& Brayne, C. (2008). Incidence of earlyonset dementias in Cambridgeshire, United Kingdom. Neurology, 71(19), 1496-1499. http://doi.org/10.1212/01.wnl.0000334277.16896.fa

Mevel, K., Desgranges, B., Baron, J.-C., Landeau, B., De la Sayette, V., Viader, F., ... Chételat, G. (2007). Detecting hippocampal hypometabolism in Mild Cognitive Impairment using automatic voxel-based approaches. NeuroImage, 37(1), 18-25. http://doi.org/10.1016/j.neuroimage.2007.04.048

Möller, C., Dieleman, N., van der Flier, W. M., Versteeg, A., Pijnenburg, Y., Scheltens, P., ... Vrenken, H. (2015). More atrophy of deep gray matter structures in frontotemporal dementia compared to Alzheimer's disease. Journal of Alzheimer's Disease: JAD, 44(2), 635-647. http://doi.org/10.3233/JAD-141230

Moodley, K. K., Minati, L., Barnes, A., Dickson, J. C., Ell, P. J., \& Chan, D. (2013). Simultaneous PET/MRI in frontotemporal dementia. European Journal of Nuclear Medicine and Molecular Imaging, 40(3), 468-469. http://doi.org/10.1007/s00259-0122315-5

Müller-Gärtner, H. W., Links, J. M., Prince, J. L., Bryan, R. N., McVeigh, E., Leal, J. P., ... Frost, J. J. (1992). Measurement of radiotracer concentration in brain gray matter using positron emission tomography: MRI-based correction for partial volume effects. Journal of Cerebral Blood Flow and Metabolism: Official Journal of the International Society of Cerebral Blood Flow and Metabolism, 12(4), 571-583. http://doi.org/10.1038/jcbfm.1992.81

Muñoz-Ruiz, M. Á., Hartikainen, P., Koikkalainen, J., Wolz, R., Julkunen, V., Niskanen, E., ... Soininen, H. (2012). Structural MRI in frontotemporal dementia: comparisons between hippocampal volumetry, tensor-based morphometry and voxel-based morphometry. PloS One, 7(12), e52531. http://doi.org/10.1371/journal.pone.0052531

Neary, D., Snowden, J. S., Gustafson, L., Passant, U., Stuss, D., Black, S., ... Benson, D. F. (1998). Frontotemporal lobar degeneration: a consensus on clinical diagnostic criteria. Neurology, 51(6), 1546-1554. Retrieved from http://www.ncbi.nlm.nih.gov/pubmed/9855500

Nyatsanza, S., Shetty, T., Gregory, C., Lough, S., Dawson, K., \& Hodges, J. R. (2003). A study of stereotypic behaviours in Alzheimer's disease and frontal and temporal variant frontotemporal dementia. Journal of Neurology, Neurosurgery, and Psychiatry, 74(10), $1398-1402$.

Pasquier, F., Grymonprez, L., Lebert, F., \& Van der Linden, M. (2001). Memory impairment 
differs in frontotemporal dementia and Alzheimer's disease. Neurocase, 7(2), 161-171. http://doi.org/10.1093/neucas/7.2.161

Perry, D. C., Whitwell, J. L., Boeve, B. F., Pankratz, V. S., Knopman, D. S., Petersen, R. C., ... Josephs, K. A. (2012). Voxel-based morphometry in patients with obsessivecompulsive behaviors in behavioral variant frontotemporal dementia. European Journal of Neurology: The Official Journal of the European Federation of Neurological Societies, 19(6), 911-917. http://doi.org/10.1111/j.1468-1331.2011.03656.x

Piguet, O. (2011). Eating disturbance in behavioural-variant frontotemporal dementia, 589593. Retrieved from http://www.ncbi.nlm.nih.gov/pubmed/21584651

Piguet, O., Hornberger, M., Mioshi, E., \& Hodges, J. R. (2011). Behavioural-variant frontotemporal dementia: diagnosis, clinical staging, and management. The Lancet. Neurology, 10(2), 162-172. http://doi.org/10.1016/S1474-4422(10)70299-4

Piguet, O., Hornberger, M., Shelley, B. P., Kipps, C. M., \& Hodges, J. R. (2009). Sensitivity of current criteria for the diagnosis of behavioral variant frontotemporal dementia. Neurology, 72(8), 732-737. http://doi.org/10.1212/01.wnl.0000343004.98599.45

Pijnenburg, Y. A. L., Gillissen, F., Jonker, C., \& Scheltens, P. (2004). Initial complaints in frontotemporal lobar degeneration. Dementia and Geriatric Cognitive Disorders, 17(4), 302-306. http://doi.org/10.1159/000077159

Piolino, P., Chételat, G., Matuszewski, V., Landeau, B., Mézenge, F., Viader, F., ... Desgranges, B. (2007). In search of autobiographical memories: A PET study in the frontal variant of frontotemporal dementia. Neuropsychologia, 45(12), 2730-2743. http://doi.org/10.1016/j.neuropsychologia.2007.04.013

Pitel, A.-L., Aupée, A.-M., Chételat, G., Mézenge, F., Beaunieux, H., de la Sayette, V., ... Desgranges, B. (2009). Morphological and glucose metabolism abnormalities in alcoholic Korsakoff's syndrome: group comparisons and individual analyses. PloS One, 4(11), e7748. http://doi.org/10.1371/journal.pone.0007748

Quarantelli, M., Berkouk, K., Prinster, A., Landeau, B., Svarer, C., Balkay, L., ... Salvatore, M. (2004). Integrated software for the analysis of brain PET/SPECT studies with partialvolume-effect correction. Journal of Nuclear Medicine: Official Publication, Society of Nuclear Medicine, 45(2), 192-201. Retrieved from http://www.ncbi.nlm.nih.gov/pubmed/14960635

Rabinovici, G. D., Seeley, W. W., Kim, E. J., Gorno-Tempini, M. L., Rascovsky, K., Pagliaro, T. A., ... Rosen, H. J. (2007). Distinct MRI atrophy patterns in autopsy-proven Alzheimer's disease and frontotemporal lobar degeneration. American Journal of Alzheimer's Disease and Other Dementias, 22(6), 474-488. http://doi.org/10.1177/1533317507308779

Rascovsky, K., Hodges, J. R., Kipps, C. M., Johnson, J. K., Seeley, W. W., Mendez, M. F., ... Miller, B. M. (2007). Diagnostic criteria for the behavioral variant of frontotemporal dementia (bvFTD): current limitations and future directions. Alzheimer Disease and Associated Disorders, 21(4), S14-18. http://doi.org/10.1097/WAD.0b013e31815c3445

Rascovsky, K., Hodges, J. R., Knopman, D., Mendez, M. F., Kramer, J. H., Neuhaus, J., ... Miller, B. L. (2011). Sensitivity of revised diagnostic criteria for the behavioural variant of frontotemporal dementia. Brain, 134(9), 2456-2477. http://doi.org/10.1093/brain/awr179 
Richards, B. A., Chertkow, H., Singh, V., Robillard, A., Massoud, F., Evans, A. C., \& Kabani, N. J. (2009). Patterns of cortical thinning in Alzheimer's disease and frontotemporal dementia. Neurobiology of Aging, 30(10), 1626-1636. http://doi.org/10.1016/j.neurobiolaging.2007.12.019

Rohrer, J. D., Ridgway, G. R., Modat, M., Ourselin, S., Mead, S., Fox, N. C., ... Warren, J. D. (2010). Distinct profiles of brain atrophy in frontotemporal lobar degeneration caused by progranulin and tau mutations. NeuroImage, 53(3), 1070-1076. http://doi.org/10.1016/j.neuroimage.2009.12.088

Rosen, H. J., Gorno-Tempini, M. L., Goldman, W. P., Perry, R. J., Schuff, N., Weiner, M., ... Miller, B. L. (2002). Patterns of brain atrophy in frontotemporal dementia and semantic dementia. Neurology, 58(2), 198-208. Retrieved from http://www.ncbi.nlm.nih.gov/pubmed/11805245

Rousset, O. G., Ma, Y., \& Evans, A. C. (1998). Correction for partial volume effects in PET: principle and validation. Journal of Nuclear Medicine: Official Publication, Society of Nuclear Medicine, 39(5), 904-911. Retrieved from http://www.ncbi.nlm.nih.gov/pubmed/9591599

Salmon, E., Garraux, G., Delbeuck, X., Collette, F., Kalbe, E., Zuendorf, G., ... Herholz, K. (2003). Predominant ventromedial frontopolar metabolic impairment in frontotemporal dementia. NeuroImage, 20(1), 435-440. Retrieved from http://www.ncbi.nlm.nih.gov/pubmed/14527604

Schroeter, M. L., Laird, A. R., Chwiesko, C., Deuschl, C., Schneider, E., Bzdok, D., ... Neumann, J. (2014). Conceptualizing neuropsychiatric diseases with multimodal datadriven meta-analyses - the case of behavioral variant frontotemporal dementia. Cortex; $a$ Journal Devoted to the Study of the Nervous System and Behavior, 57, 22-37. http://doi.org/10.1016/j.cortex.2014.02.022

Schroeter, M. L., Vogt, B., Frisch, S., Becker, G., Seese, A., Barthel, H., ... Sabri, O. (2011). Dissociating behavioral disorders in early dementia-An FDG-PET study. Psychiatry Research, 194(3), 235-244. http://doi.org/10.1016/j.pscychresns.2011.06.009

Seeley, W. W., Crawford, R., Rascovsky, K., Kramer, J. H., Weiner, M., Miller, B. L., \& Gorno-Tempini, M. L. (2008). Frontal paralimbic network atrophy in very mild behavioral variant frontotemporal dementia. Archives of Neurology, 65(2), 249-255. http://doi.org/10.1001/archneurol.2007.38

Shimizu, S., Zhang, Y., Laxamana, J., Miller, B. L., Kramer, J. H., Weiner, M. W., \& Schuff, N. (2010). Concordance and discordance between brain perfusion and atrophy in frontotemporal dementia. Brain Imaging and Behavior, 4(1), 46-54. http://doi.org/10.1007/s11682-009-9084-1

Snowden, J. S., Bathgate, D., Varma, A., Blackshaw, A., Gibbons, Z. C., \& Neary, D. (2001). Distinct behavioural profiles in frontotemporal dementia and semantic dementia. Journal of Neurology, Neurosurgery, and Psychiatry, 70(3), 323-332. Retrieved from http://www.ncbi.nlm.nih.gov/pubmed/11181853

Tan, R. H., Wong, S., Hodges, J. R., Halliday, G. M., \& Hornberger, M. (2013). Retrosplenial cortex (BA 29) volumes in behavioral variant frontotemporal dementia and Alzheimer's disease. Dementia and Geriatric Cognitive Disorders, 35(3-4), 177-182. http://doi.org/10.1159/000346392

Villain, N., Desgranges, B., Viader, F., de la Sayette, V., Mézenge, F., Landeau, B., ... 
Chételat, G. (2008). Relationships between hippocampal atrophy, white matter disruption, and gray matter hypometabolism in Alzheimer's disease. The Journal of Neuroscience: The Official Journal of the Society for Neuroscience, 28(24), 6174-6181. http://doi.org/10.1523/JNEUROSCI.1392-08.2008

Whitwell, J. L., Avula, R., Senjem, M. L., Kantarci, K., Weigand, S. D., Samikoglu, A., ... Jack, C. R. J. (2010). Gray and white matter water diffusion in the syndromic variants of frontotemporal dementia. Neurology, 74(16), 1279-1287. http://doi.org/10.1212/WNL.0b013e3181d9edde

Whitwell, J. L., \& Josephs, K. A. (2011). Neuroimaging in frontotemporal lobar degeneration--predicting molecular pathology. Nature Reviews. Neurology, 8(3), 131142. http://doi.org/10.1038/nrneurol.2012.7

Williams, G. B., Nestor, P. J., \& Hodges, J. R. (2005). Neural correlates of semantic and behavioural deficits in frontotemporal dementia. NeuroImage, 24(4), 1042-1051. http://doi.org/10.1016/j.neuroimage.2004.10.023

Woost, T. B., Dukart, J., Frisch, S., Barthel, H., Sabri, O., Mueller, K., \& Schroeter, M. L. (2013). Neural correlates of the DemTect in Alzheimer's disease and frontotemporal lobar degeneration - A combined MRI \& FDG-PET study. NeuroImage. Clinical, 2, 746-758. http://doi.org/10.1016/j.nicl.2013.05.008

Zhang, Y., Tartaglia, M. C., Schuff, N., Chiang, G. C., Ching, C., Rosen, H. J., ... Weiner, M. W. (2013). MRI signatures of brain macrostructural atrophy and microstructural degradation in frontotemporal lobar degeneration subtypes. Journal of Alzheimer's Disease: JAD, 33(2), 431-444. http://doi.org/10.3233/JAD-2012-121156 


\section{LEGENDS OF FIGURES}

Fig 1 Schematic representation of the procedures for analyzing MRI and PET data after registration. A: Procedure for analyses of GM atrophy and GM hypometabolism; B: Procedure for the direct voxel-based comparison between morphological and metabolism abnormalities; C: Procedure for the analysis of the variability in the individual patterns of atrophy and hypometabolism. See Pitel et al. (2009) for more details.

Fig 2 GM (in red) and metabolic (in blue) abnormalities in patients with bv-FTD compared with healthy controls. Between-group comparisons were conducted with the SPM5 twosample $t$ test routine. We used a $p$ value cutoff of $p<0.05$ Family-Wise Error correction but we also displayed the results using a more permissive threshold $\mathrm{p}<0.001$ uncorrected in order to have a global view of the pathology. Cluster size: $\mathrm{k}>160 \mathrm{~mm} 3$. On the axial slices, the right is displayed on the right. The colored bar represents the $t$ value of significant voxels.

Fig 3 Voxelwise correlations between regional GM volume loss and glucose hypometabolism in the 15 patients with bv-FTD. $\mathrm{P}<0.001$ uncorrected. Cluster size: $\mathrm{k}>160 \mathrm{~mm} 3$. On the slices, the right is displayed on the right. The colored bar represents the $r$ value of significant voxels.

Fig 4 Voxel-based comparison between morphological and metabolic abnormalities in patients with bv-FTD. Atrophy > hypometabolism contrast in orange and reverse contrast (hypometabolism $>$ GM atrophy) in green. $\mathrm{P}<0.05$ corrected for Family-Wise Error. Cluster size: $\mathrm{k}>100$ voxels. On the slices, the right is displayed on the right. The colored bar represents the $\mathrm{t}$ value of significant voxels. 
Table 1 Labelization, MNI coordinates, cluster size in number of voxels and $T$ value of the significant peaks for the SPM analyses of GM atrophy. L, Left; R, right

\begin{tabular}{|c|c|c|c|c|c|}
\hline \multirow[t]{2}{*}{ Labels } & \multirow[t]{2}{*}{$\mathrm{K}$} & \multicolumn{3}{|c|}{ MNI coordinates } & \multirow{2}{*}{$\begin{array}{l}\text { T (voxel } \\
\text { level) }\end{array}$} \\
\hline & & $\mathrm{x}$ & $\mathbf{y}$ & $\mathrm{z}$ & \\
\hline $\mathrm{R}$ inferior frontal gyrus & 36180 & 47 & -17 & -8 & 8.6 \\
\hline $\mathrm{L}$ insula & 50026 & -39 & -2 & 1 & 8.29 \\
\hline L caudate & 1079 & -8 & 13 & 10 & 7.86 \\
\hline $\mathrm{R}$ caudate & 1041 & 9 & 16 & 8 & 7.32 \\
\hline $\mathrm{R}$ thalamus & 1831 & 18 & -28 & 13 & 7.3 \\
\hline R supcrior frontal gyrus & 1485 & 26 & 62 & 22 & 7.28 \\
\hline L supcrior frontal gyrus & 329 & -16 & 69 & 0 & 7.14 \\
\hline R rectus gyrus & 1345 & 5 & 49 & -27 & 7.06 \\
\hline $\begin{array}{l}\mathrm{R} \text { inferior orbital frontal } \\
\text { gyrus }\end{array}$ & 1232 & 49 & 31 & -16 & 6.92 \\
\hline $\mathrm{R}$ anterior cingulate & 2698 & 5 & 36 & 21 & 6.85 \\
\hline $\begin{array}{l}\mathrm{L} \text { medial superior frontal } \\
\text { gyrus }\end{array}$ & 1634 & -3 & 26 & 45 & 6.71 \\
\hline$R$ caudate & 164 & 20 & -25 & 41 & 6.58 \\
\hline R supramarginal gyrus & 228 & 66 & -29 & 41 & 6.54 \\
\hline$R$ angular gyrus & 1506 & 37 & -75 & 46 & 6.53 \\
\hline R supcrior temporal gyrus & 453 & 68 & -30 & 16 & 6.25 \\
\hline L infcrior temporal gyrus & 428 & -58 & -34 & -7 & 6.18 \\
\hline L rectus gyrus & 173 & -1 & 44 & -26 & 6.11 \\
\hline $\begin{array}{l}\text { L supplementary motor } \\
\text { arca }\end{array}$ & 1151 & -3 & -10 & 57 & 6.1 \\
\hline R supramarginal gyrus & 243 & 64 & -49 & 33 & 5.87 \\
\hline $\begin{array}{l}\text { L supcrior medial frontal } \\
\text { gyrus }\end{array}$ & 172 & -2 & 52 & 7 & 5.76 \\
\hline
\end{tabular}


Table 2 Labelization, MNI coordinates, cluster size in number of voxels and T value of the significant peaks for the SPM analyze of GM hypometabolism. L, Left; R, right

\begin{tabular}{llllll}
\hline \multirow{2}{*}{ Labels } & $\mathrm{K}$ & \multicolumn{2}{l}{ MNI coordinates } & \multirow{2}{*}{$\begin{array}{l}\text { T (voxel } \\
\text { level) }\end{array}$} \\
\cline { 2 - 5 } & & $\mathrm{x}$ & $\mathrm{y}$ & $\mathrm{z}$ & \\
\hline R caudate nucleus & 666 & 10 & 14 & 12 & 7.10 \\
R inferior orbital frontal gyrus & 194 & 32 & 32 & -18 & 6.50 \\
R superior medial frontal gyrus & 684 & 22 & 24 & 62 & 6.28 \\
L superior frontal gyrus & 133 & -18 & 32 & 58 & 6.13 \\
L superior medial frontal gyrus & 341 & -2 & 24 & 44 & 6.00 \\
R superior frontal gyrus & 69 & 20 & 50 & 42 & 5.95 \\
R middle frontal gyrus & 43 & 24 & 62 & 24 & 5.89 \\
R inferior temporal gyrus & 57 & 62 & -20 & -32 & 5.78 \\
R inferior orbital frontal gyrus & 43 & 54 & 28 & -4 & 5.67 \\
L medial orbital frontal gyrus & 60 & -4 & 42 & -14 & 5.61 \\
\hline
\end{tabular}


Table 3 Regions atrophied in $80 \%$ of bv-FTD patients to $100 \%$ of bvFTD patients, extracted using the toolbox Marsbar. Only regions representing at least $10 \%$ of their label are listed below. $\mathrm{R}=$ right; $\mathrm{L}=$ left

\begin{tabular}{lll}
\hline $\begin{array}{l}\text { Percentage } \\
\text { of patients }\end{array}$ & Labels & $\begin{array}{l}\text { Number } \\
\text { of } \\
\text { voxels }\end{array}$ \\
\hline
\end{tabular}

\begin{tabular}{|c|c|c|c|}
\hline \multicolumn{4}{|l|}{ MRI } \\
\hline \multirow[t]{10}{*}{$80 \%$ of bv-FTD } & $\mathrm{R}$ amygdala & 73 & 29.4 \\
\hline & L caudate & 109 & 11.3 \\
\hline & $\mathrm{L}$ inferior orbital frontal gyrus & 357 & 21.1 \\
\hline & L Heschle gyrus & 55 & 24.4 \\
\hline & R hippocampus & 298 & 31.5 \\
\hline & $\mathrm{L}$ insula & 813 & 43.8 \\
\hline & L \& R rolandic operculum & 412 & 17.8 \\
\hline & $\mathrm{R}$ inferior temporal gyrus & 493 & 13.9 \\
\hline & R middle temporal gyrus & 564 & 12.8 \\
\hline & R supcrior temporal gyrus & 382 & 12.2 \\
\hline \multirow[t]{3}{*}{$85 \%$ of bv-FTD } & $\mathrm{R}$ amygdala & 45 & 18.1 \\
\hline & R hippocampus & 168 & 17.8 \\
\hline & $\mathrm{L}$ insula & 537 & 28.9 \\
\hline \multirow[t]{3}{*}{$95 \%$ of bv-FTD } & $\mathrm{R}$ amygdala & 27 & 10.9 \\
\hline & $\mathrm{L}$ insula & 253 & 13.6 \\
\hline & R hippocampus & 88 & 9.3 \\
\hline \multicolumn{4}{|l|}{ PET } \\
\hline \multirow[t]{4}{*}{$85 \%$ of bv-FTD } & L caudate & 120 & 12.5 \\
\hline & $\mathrm{R}$ caudate & 139 & 14 \\
\hline & $\mathrm{R}$ infcrior orbital frontal gyrus & 247 & 14.5 \\
\hline & R supcrior frontal gyrus & 478 & 11.8 \\
\hline
\end{tabular}



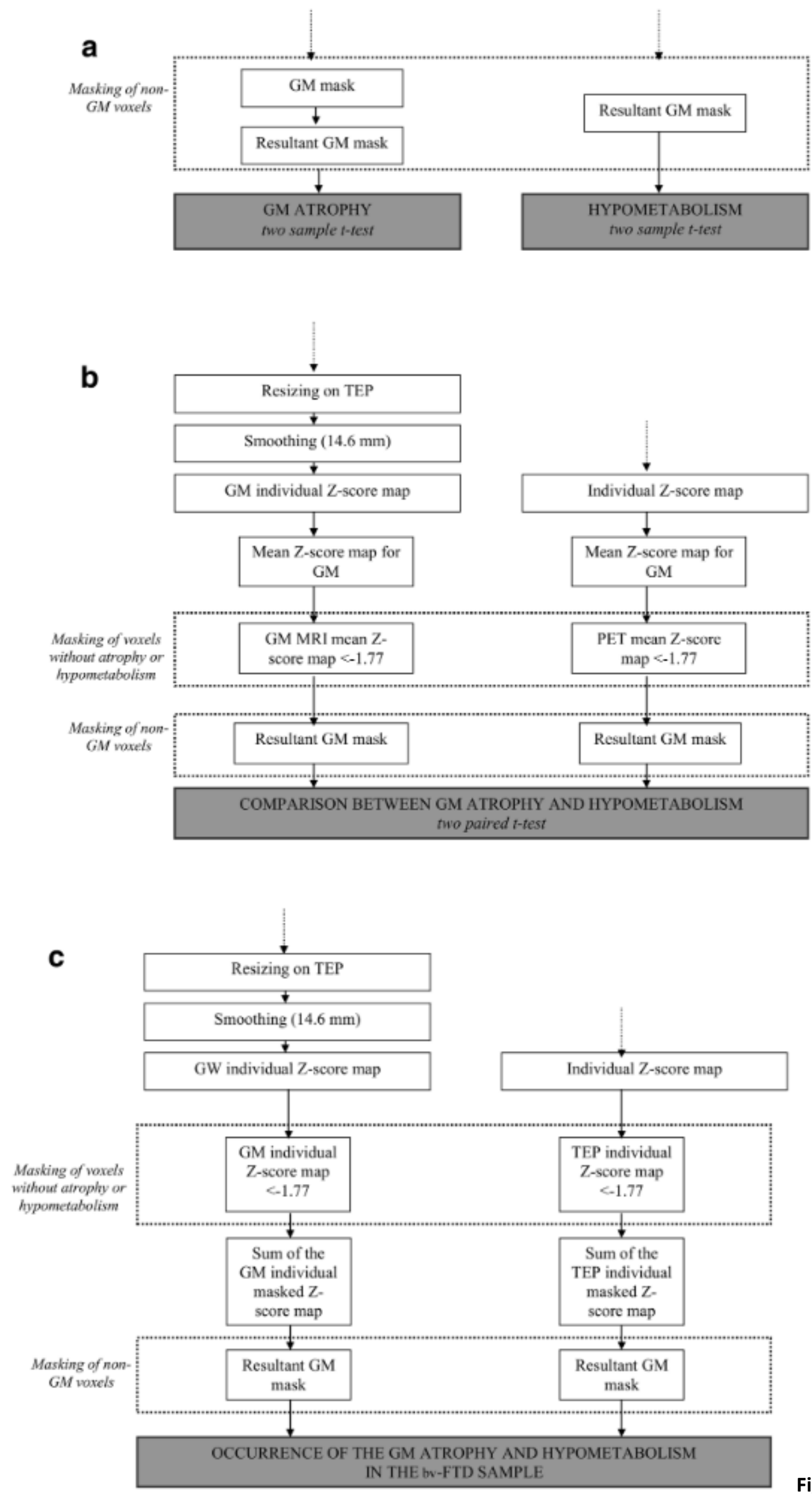

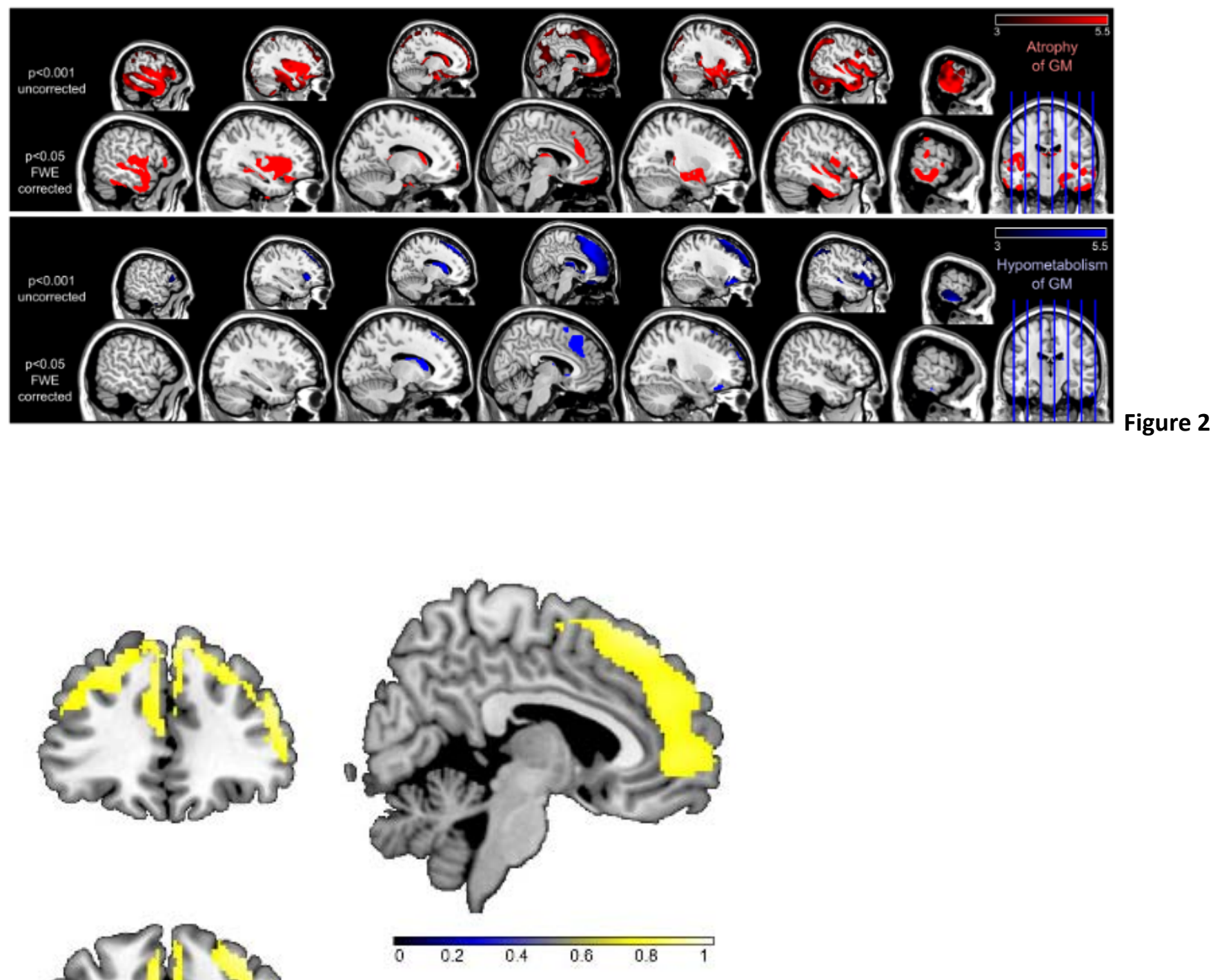

Figure 3 

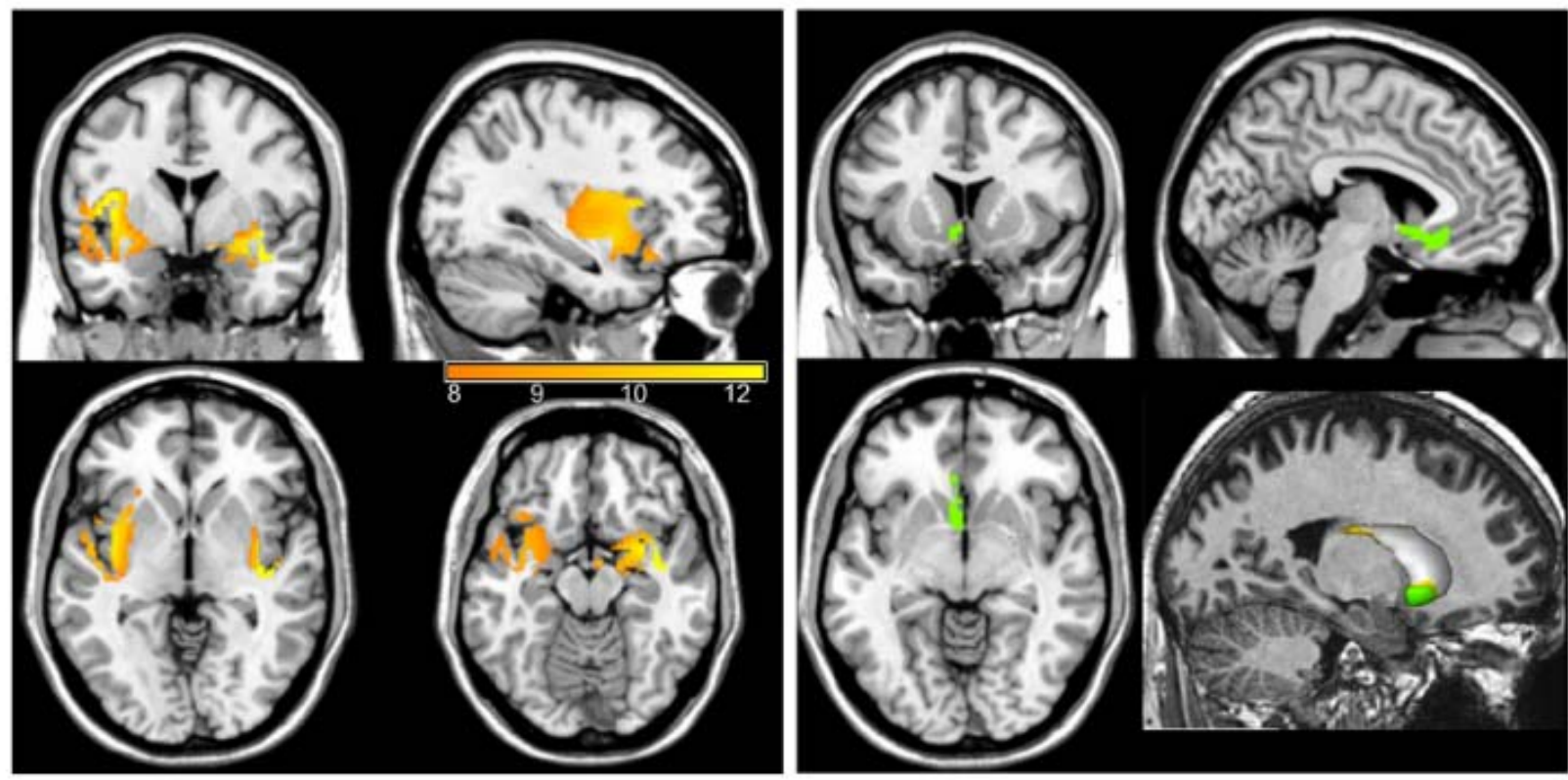

Figure 4 